\title{
Reading Ability: From Individual Development to Important Demand
}

\author{
Xuemei Deng1, Jie Sun² \\ ${ }^{1}$ School of Foreign Languages, Sichuan University of Arts and Science, Dazhou, China \\ ${ }^{2}$ Sichuan Old Revolutionary Base Development and Research Center, Sichuan University of Arts and Science, Dazhou, China \\ Email: 47872614@qq.com
}

How to cite this paper: Deng, X.M. and Sun, J. (2019) Reading Ability: From Individual Development to Important Demand. Open Access Library Journal, 6: e5329.

https://doi.org/10.4236/oalib.1105329

Received: March 12, 2019

Accepted: March 24, 2019

Published: March 27, 2019

Copyright $\odot 2019$ by author(s) and Open Access Library Inc.

This work is licensed under the Creative Commons Attribution International License (CC BY 4.0).

http://creativecommons.org/licenses/by/4.0/

\begin{abstract}
Reading is essential to individual development and national development strategy. With the improvement of technologies and the advent of emerging reading media, reading ability has gradually become indispensable for teenagers to develop their personalities, obtain knowledge and promote their social development. Meanwhile, it also concerns the cultural inheritance, technological innovation and future development of a nation, receiving more and more attention from the countries all over the world. Reading ability enhancement has become a development strategy and important demand in many countries.
\end{abstract}

\section{Subject Areas}

Linguistics

\section{Keywords}

Reading Ability, Individual Development, National Strategy,

Ways of Improvement

\section{Introduction}

Since "the reading for all" activity was specifically put forward in the $18^{\text {th }} \mathrm{Na}$ tional Congress of the CPC, encouraging a love of reading in all people has gradually become a hotspot in the society. The State Council government reports from 2014 to 2017 all advocated reading for all. Based on extensive investigation and the continuous implementation of the reading for all activity, State Administration of Press, Publication, Radio, Film and Television (SAPPRTF) formed consensus guiding document-The Development Plan of National Reading During the 13th Five Year Plan (below as the Plan). The Plan emphasizes the 
importance of reading to individual development and national development strategy. The reading quality and ability are improved through nine major programs such as holding major reading activities, improving the ability to provide reading material of quality, greatly encouraging children and teenagers to read, and enhancing the quality of digital reading. The improvement of reading ability has remained as a staunch force for promoting the development of individual mentality and body, as well as that of our society. It is a common demand for individual development and national development strategy in an era of information and globalization. Hence, the Plan noted that reading study conducted by universities and institutions should be encouraged; reading theories study from interdisciplinary perspective, research methods innovation and the construction of reading subject with greater efforts should be encouraged. It is an imminent issue waiting to be addressed for people to strengthen reading theory and discipline research, update people's reading belief and gradually cultivate their reading habits and improve reading ability in order to better promote the reading for all activity in China.

\section{Reading and Reading Ability}

What is reading? People of different times bear different opinions on this. For traditional paper media, the definition given by Modern Chinese Dictionary is correct: reading books and newspapers and understand their content. With the development of science and technology in modern times, modern reading theory offers a much more complicated definition of reading, which concerns many interdisciplinary fields such as cognitive psychology, applied linguistics, reading education, and modern hermeneutics. In his book Modern Reading, Hu Jiwu, an early scholar in China who studies modern reading, believed that reading contains three basic levels: assimilation, transformation and application. He pointed out that one is to study the process and laws of various physiological and psychological activities, such as cognition, thinking and memory, in the process of reading. The second is to study the effective transformation from the information knowledge contained in the information symbols in books (books and articles) into the theory, method and skill of personal knowledge. The third is to study the methods and measures to apply the knowledge in the book to social practice and organically combine reading and creation [1]. Introduction to Applied Linguistics compiled by Mr. Schmidt, who works in the applied linguistics research center at the University of Nottingham, is the latest achievement in the contemporary western research in the field of applied linguistics, representing the mainstream of western applied linguistic. The book sees listening, speaking, reading and writing skills as the core of applied linguistics, considering reading for different purposes can be divided into scan, skim, reading for understanding, reading to learn, reading to integrate information, and reading to evaluate critically, among which reading for understanding and reading to learn are typical. As for the two reading purposes, reading can be defined as "the reader partici- 
pates in reading not only on phonetic, lexical, syntactic, semantic and discourse level, and also participates in goal setting, chapter's main idea construction, the use of knowledge resources for interpretation, monitoring and evaluation target completion, adjustments made to strengthen understanding, and understanding process modification according to need and so on. Moreover, these processes are done in a tight, limited amount of time by aggregating activated processing and resources (in working memory)" [2]. From this, we can see that reading ability is improved and realized in the process of reading. Generally speaking, reading ability includes the following important aspects: vocabulary recognition ability, ability to integrate contextual and background knowledge, ability to grasp chapter structure and construct meaning, ability to use knowledge structures, personal experience and imagination, and assess ability and reading speed.

With the development of modern science and technology, especially marked by the development of network technology and mobile digital technology, digital reading has profoundly changed and shaped the future of reading, and reading has become accessible. The media of reading is no longer limited to printed matter. New media such as computers, mobile phones and electronic books have greatly changed the content and form of reading, and the reading experience has become richer and more convenient. This change in reading mode also brings an unpredictable prospect to human beings. We are overwhelmed by massive amounts of information every day, and reading activities become more complicated, and fragmentation, shallow reading, junk information reading become the focus of reading. According to the research results of linguistics and neuropsychology, reading is a brain's complex ability to process information independently, involving the emotion, imagination, judgment, aesthetics and many other complex brain activities of the reading subject and some higher form of language processing ability, which is reading ability.

\section{Reading Ability and Individual Development}

Reading is a complicated mental cognitive activity. According to modern reading theory research, reading, for individual, is not only a process of discovering and absorbing knowledge, an important means of learning, but also a kind of creation, and a bridge that leads people to break through their limitations. When reading, individual is not in a state of passive acceptance, but actively participates in mental process including language information processing, construction of world of meaning, cultural creation and aesthetic experience. In this sense, reading is core ability in individual development, especially for teenagers. The cultivation of reading ability is of great significance to their development.

Through research on teenagers' reading ability, domestic and foreign scholars have found that reading ability is closely linked with their individual cognitive development (feeling, imagination, memory, intelligence, emotion, etc.), language ability, knowledge accumulation and growth in the society. For this reason, countries around the world call the cultivation of reading ability of teenag- 
ers in their national reading programs "root project", such as Britain's "Reading Start Plan" and "Summer Reading Challenge Plan". They focus on promoting reading and writing ability of children and young people. The cultivation of reading ability of Children and adolescents in the United States has profound pedagogy foundation. In the early 1930s, Dewey, American education giant, passed his "experience and education", "people problems" and so on a series of education works, discusses the development pattern issue of children and adolescents' body and mind. He thinks that in childhood and adolescence, their physical and mental development is not mature, or is still in a blank state, but it's not a weakness that people generally think of. It is a time that children and adolescents learn and grow, and therefore children and adolescents can be shaped easily. This concept has been constantly recognized and strengthened in American society, thus confirming the importance of reading to the individual development of children and teenagers academically.

In our country, the cultivation of reading ability is an important goal set by Chinese Curriculum Standards during the full-time compulsory education stage. Teenagers of different ages have different requirements. In 2001, the Full-time Compulsory Education Chinese Curriculum Standards (experiment draft) promulgated by the Ministry of Education shows that in the stage of compulsory education, elementary and middle school students should "have the ability of reading independently, focus on emotional experience and accumulation, and form a good sense of language. They should learn to read in a variety of ways and be able to initially understand and appreciate literary works. They should be influenced by noble sentiment and reading interest, develop personality and enrich their spiritual world. They can read simple ancient Chinese with the help of reference books. The total volume of extracurricular reading in the nine years of study should be more than 4 million words". In 2011, the Compulsory Education Chinese Curriculum Standards (experiment draft) promulgated by the Ministry of Education has different requirements for teenagers of different ages in the cultivation of their reading ability. The "specific proposals" point out that "reading is an essential way to obtain information, know the world, develop thinking and obtain aesthetic experience through language". Reading is a personalized behavior of students, and teachers' analysis should not replace students' reading practice. "We should enable students, in active thinking and emotion activities, to deepen understanding and experience, think, obtain edification and enjoy aesthetic experience. Students' unique feeling, experience and understanding should be paid attention to". "We should emphasize on encouraging students to read extensively, expand their reading amount and improve their reading quality", and advocate multi-angle and creative reading. So to speak, the new Chinese Curriculum Standards gives new meaning to reading. It gives a more specific description of the reading ability of teenagers in different ages, especially of the development of reading ability running through every stage of individual, which is also an important part with unique features in our current 
Chinese curriculum reform.

\section{Reading Ability Has Become a Major Demand for National and Social Development}

Since the 1970s, with the economic and social development of countries around the world and the intensified competition in comprehensive national strength, the great transformation of human development marked by information technology requires greater cultural creativity in contemporary society, and culture has become a decisive force in the era of information technology and globalization. In 1992, UNESCO consultant and system philosopher E. Laszlo submitted a report Fateful Choice: the Survival of the 21 st Century to the Club of Rome. In his report, he thinks that the 21 st century distinguishes a nation from another with culture, and that "culture is not limited to pure literature, art, music and philosophy, but also shows in the way of creation of science and technology, the control of the natural environment, personal feelings of beauty and harmony, and his sense of identity to the world and his fantasy to the world". He believes that "activating cultural creativity" is a prerequisite for national and social development [3]. In terms of cultural inheritance and innovation, national reading has a fundamental and core status, which is increasingly highly valued by countries around the world. To improve reading ability has become a development strategy and major demand of many countries.

In general, the academic concept of "national reading" should be extended to the promotion of this activity by UNESCO. In 1972, the UNESCO advocated to the world "Books for All", and in 1982, it put forward "towards a Reading Society". In 1995, "World Book Day" was put forward and every 23 April was formally identified as "World Reading Day". In 1997, slogan "Reading for All” was put forward. In 2001, "World Book Capital Plan" was set up to improve reading interest and reading ability of the whole Society, and promote the book publishing. UNESCO promoted national reading from the standpoint of individual development, social progress and the future of humanity, and the reading ability enhancement program was quickly recognized and accepted by countries around the world, so as to meet the new requirements of national and social development.

Developed countries improve their reading ability through legislation. Reading has always been highly valued in the United States. The US Reading Challenge and the Excellent Reading Act were passed in 1996 by the Clinton administration, with the goal of helping children to be able to read independently by the age of 8 (grade 3 ). Reading First is one of the main themes of the Bush administration's education reform act, "never let a child fall behind", which aimed at improving the reading ability of pre-school and primary school pupils. The 2001 Reading First Initiative aims to have all pupils able to read before the third grade in five years [4]. Britain was the first country in the world who has set the "national reading year". Britain's "Reading Start Plan" is for pre-school children, 
which is a national program for guiding the youngest children into reading. The British reading association's summer reading challenge is also a long-term promotion of reading for children. In fact, whether national institutions such as the British government, the modern public library, or well-known independent agencies dedicated to reading promotion such as book companies and reading club, they are enhancing the promotion of reader's reading ability to a level of national major demand and cultural strategy, and attracting numerous social institutions, organizations and extensive social members. Developed countries such as Germany, France and Japan have adopted reading legislation to guarantee the improvement of reading ability.

It is not very long for us to put forward the concept of "national reading" and promote it in our country, but scholars, the media and government agencies respond to this major social demand fast. As Mr. Liu Binjie pointed out that "we should accurately grasp the new situation, new changes, new opportunities, new tasks and new requirements that the national reading program faces, and work together to advocate reading habits, guiding reading direction, and constructing a reading China, thus promoting the great development and prosperity of socialist culture, and facilitating the construction of learning society and a well-off society in an all-round way" [5]. From 2006 till now, reading for all has become a major cultural project and national development strategy for promoting cultural inheritance, innovation, scientific and technological progress and social harmony in China from individual to society, from theory to practice, from government work report to national legislation.

\section{Fund}

Project funded: A Major Project Research Findings of Sichuan Social Science Thirteenth-Five Year Plan Foundation (project number: SC18EZD024).

\section{Conflicts of Interest}

The authors declare no conflicts of interest regarding the publication of this paper.

\section{References}

[1] Hu, J.W. (1991) Modern Reading. Sun Yat-sen University Press, Guangzhou.

[2] Schmidt (2010) Introduction to Applied Linguistics. Translated by Xu Jingning, World Book Publishing Company, Guangzhou, 266.

[3] Laszlo, E. (1997) Fateful Choice: The Survival of the 21st Century. Life, Reading, New Knowledge Sanlian Bookstore, Beijing, 112.

[4] Xu, G.J. (2015) Promotion of Reading for Children and Adolescents in the United Kingdom, the United States and Singapore, Case Analysis and Inspiration. Library Journal, No. 4, 43.

[5] Liu, B.J. (2012) Promoting the Construction of Nationwide Reading and a Reading China. No. 6, China Publishing, Beijing. 